\title{
A CONCEPÇÃO SOCIEDADE/NATUREZA REDIMIDA PELA QUESTÃO AMBIENTAL CONTEMPORÂNEA
}

Tereza Coni Aguiar Geógrafa e Consultora para Meio Ambiente e Desenvolvimento tconibr@yahoo.com.br

\begin{abstract}
RESUMO
O presente artigo faz um breve percurso pela abordagem sociedade/natureza refletindo sobre alguns de seus conceitos, princípios e contribuições mais significativas. Passando pela Geografia Humana, Geografia Crítica e Geografia Humanística destaca os seus pontos relevantes e suas limitações. Ao abordar o momento atual, assinala o proveitoso diálogo com outras ciências e a importância da crescente demanda de estudos ambientais para fins pragmáticos. O presente artigo conclui que a abordagem sociedadenatureza, preocupação que sempre esteve presente na Ciência Geográfica, adquire cada vez mais um renomado desempenho no âmbito de um conhecimento estratégico.

Palavras-chave: Geografia Humana. Meio Ambiente. Sociedade/Natureza. Complexidade. Problemas Ambientais.
\end{abstract}

\section{RESUMEN}

El presente artículo hace un breve recorrido por el tema sociedad/naturaleza reflexionando sobre algunos de sus conceptos, principios y contribuciones más significativas. Pasando por la Geografía Humana, Geografía Crítica y Geografía Humanística destacando sus puntos relevantes y sus limitaciones. Al abordar el momento actual, señala el provechoso diálogo con otras ciencias y la importancia de la creciente demanda de estudios ambientales para fines pragmáticos. Concluyendo el artículo que la revalorización del tema sociedad/naturaleza como preocupación que siempre estuvo presente en la Ciencia Geográfica adquiere cada vez más un renombrado desempeño en el ámbito de un conocimiento estratégico.

Palabras clave: Geografía Humana. Medio Ambiente. Sociedad/Naturaleza. Complejidad. Problemas Ambientales. 


\section{Introdução}

O presente artigo procura fazer uma breve retrospectiva dos principais elementos que nortearam o pensamento geográfico no que concerne à relação sociedade/natureza e abordar questões trazidas por novos paradigmas que são de interesse para os estudos ambientais.

Do ponto de vista teórico e metodológico, uma pergunta permeou o trabalho semelhante ao que Max Derruau (1964) fez na década de 1950, quando, segundo ele, a Geografia Humana passava por uma autêntica crise: é possível incorporar à perspectiva da relação homem/meio novos aportes conceituais e teóricos considerados válidos para os estudos ambientais?

A complexidade da questão ambiental que emergiu na virada da década de sessenta para setenta e que foi incrementada a partir dos anos de 1990, expôs ainda mais a Geografia ao diálogo entre os diversos paradigmas e saberes científicos. Neste sentido, procura-se refletir se a abertura trazida por estes estudos, efetivamente, se conciliam e contribuem para o saber e o fazer geográfico.

Geografia da relação sociedade/natureza: um paradigma em contínua renovação

O paradigma da relação sociedade/natureza, embora imprescindível para os estudos ambientais, esteve praticamente afastado da pesquisa geográfica nas décadas de 1960, 1970 e 1980, só retomado a partir do surgimento da questão ambiental que demandou preocupações em termos de linha de pesquisa e lançou novos desafios metodológicos à ciência geográfica.

Esta perspectiva da pesquisa geográfica teve o seu desenvolvimento afetado por uma das dicotomias clássicas: a da Geografia Física e a da Geografia Humana. A Geografia Física compreendia os estudos dos aspectos naturais e a Geografia Humana dedicava-se aos estudos relacionados às atividades humanas. Este fato se deve, principalmente, à existência de um arcabouço metodológico mais eficiente das ciências físicas, conforme assinalou Christofoletti (1985):

(...) a Geografia Física rapidamente ganhou a imagem de ser a parte cientificamente mais bem consolidada e executada(...). Destituída de aparato teórico e explicativo para as atividades humanas, assim como da imprecisão dos procedimentos metodológicos, a Geografia Humana sempre se debatia na procura de justificar o seu gabarito científico e em estabelecer sua definição e finalidades como ciência. (p.13). 
A chamada revolução quantitativa e teorética da geografia, iniciada no final da década de 1960, tentou superar esta defasagem quando procurou elevar a Geografia a um status científico. A Nova Geografia, como ficou conhecida, consagrou o positivismo caracterizando-se pelo pragmatismo, exigência de leis, comprovação de hipóteses, valorização excessiva de dados estatísticos e rigor quanto à utilização do método científico. Os pressupostos inerentes à Nova Geografia, já reivindicados em décadas anteriores, ao se afirmarem, afastaram ainda mais as pesquisas relacionadas à geografia da relação sociedade/natureza, como uma perspectiva teórico conceitual a ser adotada. Foi um período em que surgiram novas especializações e as dicotomias então existentes foram reforçadas. Pode-se até afirmar que as exigências impostas pelas idéias que passaram a dominar colocaram a Geografia Humana como um estudo “menor”, sem a qualificação requerida pela moderna ciência, ficando praticamente relegada ao ostracismo.

Considera-se que as contribuições advindas da nova geografia, a partir do final da década de 1960, para o campo das relações entre sociedade e natureza tenham sido muito reduzidas. Excetua-se daí a preocupação com padrões espaciais, que auxiliam os estudos ambientais, em especial na parte referente a zoneamento, e necessitam do aporte referente às concepções de ordenamento e organização espacial.

As limitações impostas pelo Método Científico, especialmente o reducionismo e a restrição a novos temas demandados pela sociedade contemporânea (entre os quais os estudos ambientais), logo se fizeram sentir, e os resultados das pesquisas que adotaram seus pressupostos geraram insatisfação, não alcançando em muitos casos as expectativas ajuizadas. Seguiu-se, então, uma fase de busca de novos paradigmas e valores cuja diversidade de abordagens renovou a Ciência Geográfica, sendo a perspectiva centrada na relação sociedade/natureza discutida a partir de novos aportes teóricos incorporados neste processo.

Fazendo-se uma breve retrospectiva observa-se que a abordagem da relação sociedade/natureza recebeu, só no fim do século XIX e início do século XX contribuições definidoras desta linha de pensamento geográfico. Colaboraram para esta abordagem metodológica dois mestres: Ratzel, na Alemanha, associado ao Determinismo Geográfico e Paul Vidal de La Blache, na França, alinhado ao 
possibilismo. Notadamente, os estudos de La Blache foram divulgados em todo mundo e influenciaram sobremaneira esta perspectiva da Geografia brasileira. Recentemente passaram por novas leituras que deram oportunidade de reavaliar as críticas a eles impostas e as contribuições que trouxeram à Geografia.

La Blache (1985, p.41) afirma que "o campo de estudo, por excelência, da Geografia é a superfície”. Para ele, o objeto da Geografia abarca os fenômenos que se produzem na zona de contacto entre massas sólidas, líquidas e gasosas que conformam o planeta. Assim, a Geografia compreende o conjunto da Terra que sofre a participação de uma dinâmica geral. O princípio da unidade é outra idéia base para a Geografia Humana de La Blache, a que lhe outorga o patamar de ciência. A razão para esta atribuição está ligada ao fato de a noção de unidade encontrar significado na correspondência ou correlação dos fenômenos observados na superfície terrestre e comparados entre si. Segundo La Blache (1985),

A análise desses elementos, o estudo de suas relações e de suas combinações compõem a trama de toda pesquisa geográfica (...) Estas causas, se é permitido usar esta palavra ambiciosa, ao se combinar originam as variedades sobre as quais o geógrafo trabalha. (p. 41).

A noção de meio para La Blache (1985, p. 45) vem da observação dos inúmeros elos existentes entre diversos elementos, que juntos, adquirem a noção de complexidade. Os elementos constantes de determinada fração da superfície terrestre “se apresentam a nós em grupos organizados, em associações regidas por um equilíbrio que o homem perturba incessantemente ou, conforme os casos, retifica colocando a mão”. Por tais características, a Geografia, nesta perspectiva que se apresenta, segundo La Blache, na mesma obra, dá à descrição e à observação, um papel preponderante:

\footnotetext{
Não seguramente que renuncie à explicação: o estudo das relações dos fenômenos, de seu encadeamento e de sua evolução são também caminhos que levam a ela. Mas esse objeto mesmo a obriga, mais que em outra ciência, a seguir minuciosamente o método descrito. Uma dessas tarefas principais não é localizar as diversas ordens de fatos que a ela concernem determinar exatamente a posição que ocupam, as áreas que abrangem? Nenhum índice, mesmo nenhuma nuança não poderia passar despercebida; cada uma tem seu valor geográfico, seja como dependência, seja como fator, no conjunto que se trata de analisar. É preciso, então, tomar sobre o fato cada uma das circunstâncias que o caracterizam, e estabelecer exatamente o resultado. No rico teclado de formas que a natureza expõe a nossos olhos, as condições são tão diversas, tão intercruzadas, tão complexas, que elas arriscam escapar a quem acredita tê-las cedo demais. (p. 41).
}

Para concluir este texto escrito em 1913 - “As Características Próprias da Geografia” - La Blache (1985, p.46) assinala que, neste conjunto de elementos, o 
homem se impõe direta ou indiretamente, por sua presença, por suas obras ou pelas conseqüências de suas obras. Considera o homem um fator geográfico de primeira ordem, “ um dos agentes poderosos que trabalham para modificar as superfícies ... Pode se dizer que dele depende o equilíbrio atual do mundo vivo”. A obra do homem na Terra, por ser longa, necessita ainda da História, Geografia e História devem estar juntas, embora tenham métodos e pontos de vista distintos.

Neste mesmo texto, observa-se que La Blache já manifesta idéias que ganharam força na atualidade nas pesquisas ambientais: a noção de complexidade e a do homem como responsável pelo equilíbrio do mundo vivo, ou seja, do meio geográfico. Assim, lança um embrião para a noção de impacto ambiental e destaca o papel que têm, para o meio, as transformações oriundas de suas ações, quando menciona a importância do homem no elo de relações tendo em vista "as consequências de suas obras".

A complexidade das questões que emergem da prática e do campo de reflexão da Geografia não é de todo recente, especialmente no campo de interesse do presente artigo, ou seja, as teorias geográficas que abarcam a relação sociedade/natureza. Este paradigma que chegou recentemente ao debate nas ciências, especialmente por Edgar Morin, era praticamente desconhecido na Geografia. No entanto, Ratzel já pensava no tema da complexidade, tendo para ele adquirido papel relevante na Ciência Geográfica e no pensamento moderno das ciências.

Segundo Carvalho (2004 p. 73), Ratzel preocupa-se com as conexões existentes entre todas as coisas presentes na Terra. A análise da obra de Ratzel aponta para um amplo conjunto de interesses de pesquisa, que desemboca num novo campo de conhecimento - a antropogeografia. Esta considerava que não se deveria estabelecer limites claros entre ciências como a História, a Biologia, a Etnografia e a Geografia, propagando um movimento no início do século XX de integração de saberes. Esta perspectiva trazida por Ratzel situa-se à frente de seu tempo. Hoje a integração dos saberes é um dos temas de interesse na Ciência, especialmente nas pesquisas ambientais que ressaltam a relevância da interdisciplinaridade e da transdisciplinaridade (p.71), sendo as questões ambientais colocadas com um eixo transversal pelo qual perpassam diversas disciplinas.

Demangeon (1985, p.52) em seu texto Uma Definição da Geografia Humana publicado em 1952, após sua morte e transcrito do livro Problèmes de Géographie 
Humaine questiona a definição de Geografia Humana como o estudo das relações do homem com o meio, considerando-a muito ampla, sendo impossível dar-se conta de tal abrangência. Principalmente, chama a atenção para o fato de que muitas relações existentes não são propriamente o foco da Ciência Geográfica. Sugere, então, uma segunda definição que abandona a noção de homem como indivíduo, que seria mais pertinente ao objeto da antropologia e da medicina, e introduz a noção de sociedade.

Segundo Demangeon, o que a Geografia estuda são os homens em coletividade e grupamentos: são as ações do homem em sociedade. Adota como definição da Geografia Humana “o estudo das relações dos grupamentos humanos com o meio geográfico”. Demangeon tráz uma contribuição importante à questão ambiental, pois incorpora o termo "geográfico", que considera mais apropriado que ambiente físico. Para ele, a noção de meio geográfico "engloba não somente as influências naturais que se podem exercer, mas ainda uma influência que contribui para formar o meio geográfico, o ambiente total, a influência do próprio homem.” Complementando estas idéias de fundamental importância para os estudos ambientais na atualidade e, especialmente, para a construção do conceito de meio ambiente, Damangeon (1985), ressalta que, graças à sua inteligência e iniciativa, o homem é um elemento que exerce sobre o meio uma ação poderosa. “(...) e essa ação das sociedades humanas sobre a natureza é tanto mais rica e mais forte quando as suas iniciativas as têm tornado mais capazes de ampliar seu raio de ação, de alcançar mais” (p.52). Veja-se, por exemplo, as idéias contidas no texto que se segue, no qual Demangeon, na mesma obra atribui o papel relevante da ciência (tecnologia) e dos transportes como elemento formador do ambiente, em que o conceito de meio/ambiente inclui o homem.

Em nossos dias, a ação do homem sobre a natureza está se ampliando ainda mais em razão das armas que a ciência lhe tem dado e do domínio que os transportes lhe asseguram sobre as distâncias. Dessa maneira, as obras humanas oriundas de todo o passado da Humanidade contribuem para constituir o meio, o ambiente, o meio geográfico que condiciona a vida dos homens (p.53).

Apesar de falar de condicionamento, Demageon deixa bem claro, quando discorre sobre os princípios, essenciais ao método geográfico, que não existe um determinismo absoluto e, sim, possibilidades de que as iniciativas do homem podem dispor. Para ele, não há fatalidades, mas vontade humana. Sobre a questão da 
causalidade, observa-se que já apresenta um novo elemento e uma visão que se distingue da relação direta de causa e efeito, tal como assinala no trecho a seguir:

Não se deve crer em Geografia Humana numa espécie de determinismo brutal, numa fatalidade resultante dos fatores naturais. A causalidade em Geografia Humana é muito complexa. Com sua vontade e suas iniciativas o próprio homem é uma causa que traz perturbações àquilo que poderia parecer a ordem natural.(p.55).

Complementa os princípios, considerando que a Geografia Humana trabalha a partir de uma base territorial e este elemento é o que diferencia a Geografia de outras ciências. Destaca ainda que é preciso observar a evolução dos fatos; para tanto, tornase imprescindível recorrer à História, sem a qual a compreensão dos mesmos nos escaparia. É interessante observar que Demangeon, (1985) ao tratar do princípio relacionado à base territorial, ressalta a idéia de singularidade, quando descreve:

\footnotetext{
Esses habitats onde os homens se agrupam, onde eles trabalham, são de dimensões muito desiguais que podem ir da localidade elementar ao grande território. Eles formam os quadros no interior dos quais se distribuem os fatos geográficos e, por seus caracteres próprios, imprimem uma originalidade para a Humanidade que aí se concentra. Compreender e descrever essas unidades regionais é uma das funções primordiais da Geografia, porque cada uma delas forma freqüentemente uma espécie de personalidade que é preciso reviver...., porque geralmente só se consegue conceber os grandes conjuntos pela análise de pequenos pays que a compõem; para melhor abranger os fatos gerais é bom partir do particular, do localizado, do regional, observar o que a região contem de particular (o grifo nosso) e seus horizontes, suas plantas, seus habitantes e definir alguma coisa de animado que resulta da união de um fragmento de terra com um grupo humano. (p.56).
}

Outra contribuição a ser assinalada na abordagem sociedade/natureza é a de Marx Derruau. Notabilizando-se pela grande habilidade de sistematização, produziu, neste campo, obras de referência entre as quais o Tratado de Geografia Humana, que foi publicado na década de 1960. Nesta obra, Derruau (1961), parte da colocação de que a Geografia viveu uma verdadeira crise decorrendo, deste fato, a existência de geógrafos que se apegavam aos enfoques clássicos, enquanto outros se aventuravam, dedicandose a novos aspectos. Chamando o resultado destes estudos de uma "Nova Geografia” como aquela que foi enriquecida com uma série de tendências e métodos, apresenta uma definição dos objetivos e dos limites da Geografia Humana do período por ele analisado (p.1).

É interessante destacar suas reflexões acerca do objeto da Geografia, pois trazem elementos pertinentes ao mundo atual e globalizado. Para ele, dizer que a Geografia é a ciência do homem-habitante é muito vago. Dizer que é a ciência do homem-produtor- 
consumidor (grifo nosso) é limitado, pois o homem é também um ser religioso e que dispõe de tempo livre. Faz ainda uma crítica à conceituação de Demangeon, quando este define a Geografia Humana como o estudo das relações dos grupamentos humanos com o meio geográfico, considerando que meio geográfico quer dizer pouco, já que de tão artificial chega a ser sinônimo de grupo humano.(p.15). Ressalta, com bastante propriedade, que se deve levar em conta que os vínculos que explicam a vida de determinados grupos não mais dependem somente do meio ambiente imediato, mas podem estar localizados em outro extremo do mundo. Assim, Derruau (1961) apresenta como geografia

(...)a ciência das múltiplas relações que explicam a implantação dos homens com seus modos de vida dentro de um marco espacial. O objeto da Geografia é sempre uma combinação espacial. (p.20)

Ao discorrer sobre os princípios da Geografia, Derruau chama a atenção para aspectos bastante atuais e de relevância para os estudos ambientais: o princípio de extensão ou localização que abarcaria a idéia de que todo fenômeno deva ser localizado e a sua área delimitada. Porém, alerta que não basta localizar num mapa ou apenas cartografar, pois equivaleria a considerar uma técnica como um objeto em si. Para ele, o mapa é um ponto de partida.

O princípio da generalização formulado por Emmanuel de Martone baseava-se na preocupação de encontrar elementos análogos. Na mesma obra Derruau complementa esta noção afirmando que se deve também preocupar-se com os fenômenos diferentes, assinalando que nunca há um fenômeno idêntico ao que se está estudando: “O mundo é diversidade” (p.17).

Quanto ao princípio da causalidade, Derruau afirma que a Geografia é uma ciência explicativa, não nega as causas individuais, porém pondera que às vezes a noção de causa em Geografia é obscura e, portanto, cabe a possibilidade de substituí-la pela noção de relação ou conexão. Para Derruau “o Humano às vezes é contingente, entretanto a Geografia é a ciência das relações de coexistência, que nem sempre são relações de causalidade” (p.18).

Derruau ainda nos oferece uma contribuição relativa à observação, consagrando a Geografia como uma ciência do que se vê, denominando-a de uma ciência visual. Entretanto, alerta para as atividades invisíveis; por isso, a Geografia estuda o que se vê e o que quase não se vê. Aqui se pode destacar a afinidade dos estudos ambientais com 
a necessidade de observação e de se compreenderem tanto fenômenos cuja natureza é qualitativa e sensorial, mas que não podem ser vistos, quanto aqueles fenômenos que são negligenciados e não percebidos pelo conjunto da sociedade, embora, muitas vezes sejam de grande importância social.

Outro legado importante da Geografia Humana, que contribuiu para os estudos ambientais, diz respeito à obra de Jean Brunhes, geógrafo nascido na França em 1860, cuja preocupação com os recursos não renováveis “antecipa todo o debate ambiental atual, desde o problema do desmatamento ao da água, em suas vinculações com o processo de formação do espaço” (MOREIRA, 2008, p.75). Nota-se, em seus estudos, que se preocupa com a destruição dos recursos naturais falando de desflorestamento, de devastação da natureza e de uma “economia destrutiva”. Sua abordagem no trato dos fenômenos é global, já antecipando questões relativas às ações humanas que exaurem as riquezas naturais sem se preocuparem com a sua recuperação.

Como criador de um modo original de Pensamento Geográfico que denominava de Geografia Ecológica, Max Sorre antecipou o debate atual da relação da indústria com o meio ambiente e da teoria da complexidade (MOREIRA, 2008). Embora tenha considerado a complexidade das interações sociedade/natureza La Blache (1985) não chegou a formular nenhuma estrutura conceitual para embasar seu pensamento. Foi Sorre que o fez. Considerou o ecúmeno um complexo de complexos, um todo formado e caracterizado pela superposição e entrecruzamento de diferentes níveis de complexidade: o complexo agrícola, o alimentar, o patogênico, o técnico e o cultural.

Outra obra que despertou interesse nos dias atuais e assinalou uma contribuição significativa à Geografia moderna foi a de Elisée Reclus. Sua definição de Geografia é singular no que diz respeito à relação sociedade/natureza, como citado na obra de Andrade (1985), dedicado à obra do geógrafo francês:

\footnotetext{
A Geografia era uma única ciência, e a natureza e o homem, por ela estudados, formavam um conjunto harmônico em que o meio natural exercia influência sobre o homem, provocando a sua ação, modificando-o, transformando-o e conduzindo-o à produção do espaço. (p.20)
}

Com o advento da Geografia Crítica, o desenvolvimento de estudos centrados na relação sociedade/natureza são repensados à luz do marxismo, trazendo, juntamente com as demandas surgidas com a crise ambiental, o revigoramento destas análises sob o ponto de vista geográfico. 
Para a Geografia Crítica, baseada no materialismo dialético, “o objeto da Geografia é portanto a sociedade, e a Geografia viabiliza o seu estudo pela organização espacial. Em outras palavras, a Geografia representa um modo particular de se estudar a sociedade” (CORREA, 1986). A organização do espaço vai além da descrição dos padrões espaciais; procura ver as relações dialéticas entre formas espaciais e processos históricos que modelam os grupos sociais. Para Correa, a objetivação do estudo da sociedade pela Geografia faz-se através deste tipo de organização. Seus estudos se baseiam em categorias de análise: estrutura, processo, função e forma que permitem a compreensão da totalidade social e sua espacialização. Para a perspectiva marxista, o homem, para satisfação de suas necessidades intervém na natureza; deste processo, originam-se as relações sociais. Assim, a Geografia compreende o estudo das relações dos homens entre si (relações sociais) e destes com a natureza.

Neste momento, parte da Geografia passa a preocupar-se com o espaço geográfico, entendendo-o como resultado das formas como os homens organizam sua vida e suas formas de produção. A Geografia concebe a relação sociedade/natureza sob a ótica da apropriação, entendendo a natureza como recurso à produção.

Nesta perspectiva, Santos (1991) considera que a relação do homem com a natureza é progressiva e dinâmica. A natureza vai incorporando a ação do homem e dele adquirindo diferentes feições relacionadas a determinado momento histórico. Para ele, denomina-se ação humana aquela que o homem realiza sobre o meio que o rodeia, para suprir as condições necessárias à manutenção da espécie. “Toda ação do homem é trabalho e todo trabalho é trabalho geográfico”(p. 88). Segundo Santos, ainda na mesma obra, “a relação entre o homem e o seu entorno é um processo sempre renovado que tanto modifica o homem quanto a natureza”(p. 88). Foi com esta visão que o marxismo introduziu, na pesquisa geográfica e ambiental, a noção polêmica de segunda natureza, que é a natureza transformada pelo trabalho social.

Embora o marxismo tenha enriquecido a abordagem da sociedade /natureza devem-se avaliar, também, as limitações apresentadas pelo materialismo dialético para as pesquisas ambientais. Neste aspecto, destaca-se o fato de suas análises não darem ênfase ao indivíduo perante determinadas condições, em um determinado meio físico, ponderando que “ o relacionamento do homem com seu ambiente é equacionado no bojo de relações sociais historicamente determinadas. (...) As relações de trabalho e de 
propriedade, principalmente, expressam o relacionamento desigual das várias classes com a riqueza natural dos lugares onde estão inseridas (MORAES, 1994).

A abordagem do materialismo dialético trazido pela Geografia Crítica, renovou aspectos das pesquisas ambientais, notadamente no que diz respeito à compreensão dos processos gerais relacionados à Sociedade e à Natureza. Entretanto, mostrou-se restrita na avaliação local, na perspectiva da escala humana, que diz respeito a conforto, aspectos ligados à qualidade de vida, valores humanos, beleza, estética e contemplação.Ou seja: na escala do lugar, a teoria marxista não privilegia aspectos que são essenciais nas avaliações e pesquisas ambientais.

Este vazio do ponto de vista metodológico viria a ser preenchido pelas idéias inovadoras trazidas por Yi-Fu-Tuan. Tuan trouxe novos conceitos que chegaram à comunidade geográfica no final da década de sessenta, quando se instalou na Universidade de Minnesota e desenvolveu seus trabalhos de sistematização da Geografia Humanística. Com a publicação de Topofilia (1980) e Espaço e Lugar (1983), Tuan redefine conceitos centrais da Geografia e assinala esta perspectiva como um novo paradigma. Para as pesquisas ambientais, a contribuição de Tuan foi de grande relevância, permitindo ampliar os estudos centrados em uma visão de processo para agregar noções relativas à escala da vivência dos problemas humanos. Este ponto de vista agregou elementos à trajetória dos estudos relacionados ao homem com o seu meio.

A Geografia Humanística considera as diferentes formas através das quais os indivíduos sentem e pensam suas interações com o meio, levando em conta, nas suas análises, a riqueza de informações provenientes das experiências individuais e do grupo. A distinção entre espaço e lugar é uma marca para esta abordagem geográfica. Lugar é considerado aquele com que o indivíduo está familiarizado, integra-se no cotidiano e no qual mantém laços afetivos. O termo proposto por Tuan (1980) - topofilia, para designar o amor ao lugar, pode ser definido como "o elo afetivo entre a pessoa e o lugar ou ambiente físico” (p. 5). Assim compreendido, o lugar não é qualquer local, mas aquele que tem um significado emocional para as pessoas ou um determinado grupo. A noção de Espaço envolve um complexo de idéias que passam pela percepção visual, o tato, o movimento e o pensamento que, combinados, nos dão o sentido do espaço. A integração espacial e as noções de distância são consideradas mais pela afetividade do 
que pela distância física. Para Tuan (1983) “quando o espaço nos é inteiramente familiar, torna-se lugar” (p.83).

Com Tuan, valorizou-se a preocupação de entender os gostos, as preferência, as características e particularidades dos lugares bem como o ambiente com seus encantamentos, beleza, estética, personalidade, distinção, medos e magias. Tal abordagem foi de grande valia para as pesquisas ambientais e em muito auxiliam o repensar da perspectiva Geográfica da relação sociedade e natureza.

De fato, os novos parâmetros facilitaram o estudo de temas que ainda não eram explorados nas pesquisas geográficas, vindo a ampliar o espectro de preocupações que até então não faziam parte do elenco de questões da geografia quantitativa e da geografia marxista. O rigor de seus pressupostos e categorias não possibilitavam a abertura que a geografia humanística propiciou para o tratamento de temas demandados pela sociedade. As recentes idéias balançaram os geógrafos que se encontravam insatisfeitos com os resultados obtidos com as pesquisas baseadas nas referidas perspectivas. Os estudos apoiados nas idéias de Tuan enriquecem a ciência geográfica, especialmente as pesquisas ambientais, que careciam de um aval teórico para destacar aspectos qualitativos e negligenciáveis, inadequados aos pressupostos da geografia quantitativa e para analisar os aspectos na escala humana, que não encontravam respaldo na concepção do materialismo dialético.

No Brasil, Carlos Augusto de Figueiredo Monteiro, preocupando-se com a unidade da Geografia, tentou superá-la como professor propiciando a seus alunos um esforço de relacionar, com insistência, os fatos ditos físicos aos humanos, sendo que o mesmo esforço foi realizado na sua trajetória como geógrafo. Em seu livro “Geossistemas - a história de uma procura”, Monteiro (2000) retrata esta busca e muitas vezes se refere à complexidade dos fatos geográficos. Inicialmente, correlacionando clima com o meio urbano, Monteiro avançou em outras associações entre a natureza e a ocupação humana, sendo considerado, uma referência do Pensamento Geográfico Brasileiro. Em trabalho anterior (1980) intitulado “A Geografia do Brasil (1934 -1977)” Monteiro reflete sobre o papel de geógrafos que desenvolveram pesquisas nesta linha e que foram praticamente esquecidos; entre eles, cita Leuzinger, e o professor Hilgard O’Reilly Sternberg que foi responsável pela criação do Centro de Pesquisas e Geografia do Brasil e que “dirigiu suas preocupações 
para problemas em que os fatos geográficos naturais e socioeconômicos se integram perfeitamente.” (p.41)

\section{A Perspectiva Sociedade/Natureza e Abertura a Novos Diálogos}

O momento histórico que estamos vivendo, com expansão cada vez maior da tecnologia, massificação, facilidades de locomoção por todo mundo, excesso de consumo, acontecimentos idênticos ocorrem por todos os lugares nos diversos continentes, desastres ambientais se repetem e uma crise dos pensamentos e paradigmas deixam a todos perdidos. Vive-se também na Geografia este momento crítico de uma crise que abrange várias dimensões da sociedade - social, econômica, ambiental e cultural. Diante da situação vivida com o, neoliberalismo, retorna-se a mais uma crise e buscam-se caminhos para uma melhor compreensão do mundo atual e para o seu enfrentamento.

A sociedade contemporânea proporcionou maior comunicação e informação com diversos saberes científicos que falam diretamente de temas pertinentes à Geografia. O contato com tais conhecimentos trouxe, para a Ciência Geográfica, novos questionamentos e desafios, colocando em dúvida conceitos consolidados. Biólogos como Maturama (1995), Varella (1995), e o filósofo Edgar Morin (1996; 2001) constituem-se referências importantes para este momento histórico de reflexão sobre o pensamento geográfico.

O ponto de reflexão que nos remete à questão da complexidade, pode-se lembrar Morin (2001, p.27), quando diz que a Geografia é uma ciência multidimensional, vai da geologia aos fenômenos econômicos e sociais, reassume sua vocação originária e amplia-se em Ciência da Terra dos Homens.

A Geografia constitui-se numa ciência que propicia diálogo com várias ciências, e suas categorias Sociedade e Natureza são inerentes a diversas disciplinas científicas, sendo que a dimensão espacial lhe confere destaque no seio das ciências. No que diz respeito aos estudos ambientais, a Geografia necessita levar em conta e, em alguns casos, assimilar, nas suas pesquisas, diversos conceitos externos, oriundos de ciências afins. Muitos destes conceitos já se integram ao aparato conceitual das questões ambientais da atualidade, sendo igualmente importante sua adoção pela Geografia.

Dentre estes conceitos, incluem-se sustentabilidade, vulnerabilidade, contabilidade 
ambiental, compensação ambiental, resiliência, além de questões ligadas aos valores universais, à ética e à justiça ambiental.

No convívio com as equipes interdisciplinares, a Geografia se reconhece com um papel singular no desenvolvimento de projetos ambientais, do mesmo modo, que já há algum tempo, diversos campos científicos apontam a importância e a necessidade de se desenvolver a aptidão para a contextualização dos problemas vivenciados pela sociedade. Os acontecimentos entendidos de forma isolada necessitam de uma ciência que busque compreendê-los no seu contexto natural e igualmente no conjunto no qual está inserido (MORIN, 2001). Neste aspecto, a Geografia se destaca como ciência pronta para assumir de forma inequívoca esta tarefa, sendo capaz de articular saberes, acontecimentos e problemas complexos.

O desenvolvimento das Ciências da Terra e da Ecologia - ciência que recorre à múltiplas disciplinas físicas e biológicas e que se foca nos ecossistemas - revitalizou a Geografia, como assinala Morin (2001, p.29). Para ele a Geografia, “ marginalizada pelas ciências vitoriosas, privada do pensamento organizador - que vai além do possibilismo de Vidal de La Blache ou do determinismo de Ratzel - , a Geografia, que de resto, forneceu profissionais à Ecologia, reencontra suas perspectivas multidimensionais, complexas e globalizantes.”

A contribuição da Geografia para as pesquisas ambientais aguarda que se reveja a perspectiva que foi evadida dos debates, principalmente a partir da segunda metade da década de 1970 e que, como conseqüência, pouco se expôs ao confronto dos saberes para o seu maior aprimoramento. Para Almeida (1995),

(...) é necessário considerar que os geógrafos das décadas de 60, 70 e 80, quantitativos, marxistas, tecnocratas ou o nome que se queira dar, viraram as costas para a Geografia Física, e que com isso asfixiaram perigosamente a mais importante tradição da Geografia legada pelos franceses - a relação Sociedade/Meio. Tal situação somente veio apresentar modificação no final dos anos 80 e início dos 90, com a emergência dos estudos ambientais. (p.106).

Tudo indica que o período em que correntes competiam pela liderança do pensamento geográfico tenha sido superado e substituído por uma fase em que se convive com diversas idéias e paradigmas e na qual predominam a abertura à pluralidade e a busca de conciliação entre os diversos enfoques de acordo com objetivos e escalas pretendidos. A prática da pesquisa vem confirmando que os estudos do meio ambiente requerem muitas abordagens, conceitos e/ou categorias. 
A revalorização da Ciência Geográfica como aporte conceitual dos estudos ambientais

Na época atual os processos são muito ricos, este sendo por vários aspectos, um momento especial para a epistemologia da Geografia. Assim, percebe-se que a Ciência Geográfica defronta-se com a necessidade de rever sua trajetória, fazer releituras, encontrar um novo olhar e compreender as realidades que se apresentam ao mundo. Deste mergulho, pensa-se no quanto a unidade da Geografia ( essencial para a questão ambiental, que se encontra longe de estar encerrada) ainda tem pela frente: um longo caminho para incorporar contribuições que foram esquecidas pela preponderância do pensamento cartesiano e pela fragmentação excessiva do conhecimento.

A prática da pesquisa e as atividades em órgãos elaboradores de políticas públicas permite alinhavar algumas dificuldades que permeiam os debates nos quais a abordagem Sociedade/Natureza está inserida. A começar pelo conceito de meio ambiente, observando-se que ainda é comum a separação dos aspectos físicos (dimensão da Natureza) dos aspectos socioeconômicos (dimensão da Sociedade). Observa-se que o corpo técnico envolvido com as questões ambientais ainda está arraigado à dicotomia física e humana. Essa não prevalece apenas em órgão públicos, mas persiste também no ambiente da universidade, demonstrando que os avanços metodológicos e das pesquisas aparentam não ter capilaridade, pois não penetram nas instituições de forma igual e nem rápida.

É importante disseminar o conceito de meio ambiente, substituindo visões centradas na idéia de ação antrópica e de um conjunto de elementos físicos, químicos e biológicos e suas interações descoladas entre si e da sociedade. Esta visão teórica tende a reduzir o homem à espécie biológica extraindo a sua dimensão histórica e suas relações sociais e de poder. Nesse aspecto, considera-se que o meio ambiente inclui o homem, o homem inserido no contexto de suas relações sociais e sua cultura. Para Correa (1997),

(...) toda conceituação que venha excluir o homem em sua complexa plenitude é falha, incompleta pois alija o agente que simultaneamente é produtor e usuário do meio ambiente, mas por meio dele, algoz e vítima. (p.154). 
Nesta obra Correa afirma que este conceito de meio ambiente confunde-se com o de meio geográfico, encontrando-se muito além dos parâmetros estabelecidos pelas ciências da natureza.

Outra questão relevante diz respeito ao ritmo acelerado com que os processos se dão na realidade, o qual não é acompanhado pelos métodos de pesquisa na mesma sintonia com as demandas das sociedades contemporâneas. Observam-se uma grande defasagem neste sentido e obstáculos metodológicos para o aprimoramento dos processos de conhecimento da realidade. Há um paradoxo: os problemas tornaram-se mais amplos e diversificados, pois é cada vez maior a complexidade no mundo conectado. Para compreender os problemas há necessidade de um elenco grande de estudos, uma vez que a realidade muda rapidamente, tornado-se difícil de ser apreendida. O tempo proposto para os estudos é sempre criticado por ser demasiadamente longo. O mundo contemporâneo tem pressa. Este é um grande dilema dos estudos para licenciamento ambiental, apenas para citar um exemplo.

Percebe-se que a abordagem da Geografia Humana se desenvolveu, agregando novos elementos aos conceitos existentes, criando conceitos novos e tendo reconhecidos avanços, sem se distanciar da idéia de ciência que liga o social ao natural; foi-se readaptando a cada momento histórico, selecionando temas para pesquisa de acordo com a problemática em questão, acompanhando as mudanças ocorridas no processo produtivos em escala mundial. Com base no seu processo de evolução e na permanência do seu núcleo principal, esta abordagem geográfica pode ser descrita como um eixo estruturador da Geografia, essencial à compreensão dos estudos ambientais.

A despeito de ter ficado relegada a plano secundário, enquanto outras abordagens se destacavam na Ciência Geográfica, alguns elementos da Geografia Humana foram especialmente marcantes e garantem a sua permanência como paradigma na Geografia, chegando até os dias atuais. Entre outros elementos, sobressai-se o fato de que a Geografia lida com fenômenos complexos. Assim, a idéia de que as explicações devam ser continuamente reduzidas às entidades mais simples possíveis foi afastada da pesquisa geográfica e ambiental. Para Morin (1996):

(...) se existe um pensamento complexo, este não será um pensamento capaz de abrir todas as portas (como essas chaves que abrem caixas-forte ou automóveis), mas um pensamento onde estará sempre presente a dificuldade. No fundo, gostaríamos de evitar a complexidade, gostaríamos de ter idéias simples, leis simples, fórmulas simples, para compreender e explicar o que ocorre ao nosso redor e em nós. Mas, como essas fórmulas simples e essas 
leis simples são cada vez mais insuficientes, estamos confrontados com o desafio da complexidade (...). (p .274).

Outro ponto diz respeito ao fato de que a Geografia lida com síntese, sendo mais útil e relevante para essa área do conhecimento, quando se tem uma realidade cujos fenômenos naturais e sociais estão cada vez mais interligados. Lida também com questões cujas causas são múltiplas e interconectadas, constituindo-se num conjunto que facilita a emergência de problemas ou fenômenos.

As pesquisas ambientais necessitam abordar os constantes impactos provenientes das injunções mundiais sobre os lugares e, sendo as variações físicas e de formas de ocupação humanas muito grandes, torna-se altamente relevante detectaremse pequenas alterações de localização, de declividade, de exposição ao sol, de posição em relação à cidades próximas ou às vias de circulação, entre muitos outros aspectos. Estas singularidades podem apresentar implicações de interesse significativo para o planejamento e os estudos ambientais , razão pela qual devem ser destacadas.

Para pesquisa ambiental, foi importante, também, a aceitação como material de estudo os fenômenos não mensuráveis e a inclusão nas análises dos aspectos qualitativos, negligenciáveis, invisíveis e/ou intangíveis. A dimensão cotidiana do homem foi da mesma forma incorporada às avaliações e pesquisas, o que contribuiu, de forma positiva, na elaboração de políticas públicas, ao serem levados em conta aspectos que antes eram julgados banais.

Outra questão que assegura a perspectiva Sociedade/Natureza é a idéia de ordem espacial. O espaço ( formação e organização espacial) constitui-se parte integrante de uma determinada sociedade. A organização espacial "procura ver as relações dialéticas entre as formas espaciais e processos históricos que modelam os grupos sociais” (CORREA, 1986). Entretanto, estudos recentes da Biologia recuperam a noção de ordem sob o ponto de vista da natureza e ressaltam a necessidade de considerar organização, padrões e ritmos, que são inerentes à natureza, como conteúdos essenciais para estudos geográficos e ambientais, pois estão incorporados à vida cotidiana e social.

\section{Considerações Finais}

O reconhecimento da Geografia como disciplina cujo modo particular de pensar os problemas sociais e ambientais - através da perspectiva espacial e de saber 
lidar com um conjunto de elementos interconectados e complexos -, vem sendo gradativamente percebido, levando-a a assumir um papel de relevância no mundo atual. Por ser, também, capaz de entender o contexto nas suas diversidades de lugares e de espaços, adquire cada vez mais, na contemporaneidade, um renovado desempenho no âmbito do conhecimento estratégico.

Sendo disciplina tradicionalmente capaz de compreender a questão ambiental, que no mundo atual emerge como prioritária para a vida do planeta e da humanidade, teve suas funções revalorizadas como importante instrumento para fins pragmáticos. Sua valorização como ciência que utiliza conceitos e métodos considerados fundamentais à análise da questão ambiental contemporânea, coloca a Geografia num papel singular no conjunto das ciências.

A Geografia Humana, originalmente entendida como o estudo das relações do homem com o meio, encontra relação direta com os estudos ambientais e a demanda existente no mundo atual. O conhecimento de sua trajetória virá fortalecer a pesquisa ambiental e a própria Geografia, ampliando seu horizonte e possibilidades de ação futura.

Referências

ALMEIDA, Roberto Schmidt de. Repensando a questão do Hábitat no Brasil. Revista Brasileira de Geografia. Rio de Janeiro, v.57, n.4, p.45-58, out/dez. 1995.

ANDRADE, Manuel Correia de. Élisée Reclus. São Paulo: Ática, 1985.

CARVALHO, Marcos Bernardino de. Geografia ciência do complexus. Ensaios Transdisciplinares: Geografia e complexidade. Aldo A. Dantas da Silva, Alex Galeno (Org.). São Paulo: Sulina, 1998, p. 67-123.

CHRISTOFOLETTI, Antonio. Perspetivas da Geografia. In: As Perspectivas dos Estudos Geográficos. São Paulo: Difel, 2.ed., 1985, p.11-36.

CORREA, Roberto Lobato. Região e Organização Espacial. São Paulo: Ática, 1986, p.5-19.

Trajetórias Geográficas. São Paulo: Bertrand Brasil, 1997, 304 p.

DAMANGEON, Albert.Uma Definição da Geografia Humana. In:CHRISTOFOLETTI, Antonio. Perspectiva da Geografia. São Paulo: Difel, 1985, p.49-57 .

DERRUAU, Max. Tratado de Geografia Humana. Tradução por Raimundo Griñó, Paris: Vicens-Vives, 1961, 681p. Tradução de Précis de Géographie Humaine. 
LA BLACHE, Paul Vidal de. As Características Próprias da Geografia. In: CHRISTOFOLETTI, Antonio. Perspectivas da Geografia. São Paulo: Difel, 2.ed., 1985, p.37-47.

MATURANA R., Humberto; VARELA G., Francisco. A Árvore do Conhecimento: As bases biológicas do entendimento humano. Traduzido por Jonas Pereira dos Santos. São Paulo: Psy II, 1995.

MENDONÇA, Francisco de Assis, LOWEN-SAHR, Cicilian Luiza, SILVA, Márcia da. (Org). Espaço e Tempo: Complexidade e Desafios do Pensar e do Fazer Geográfico. Curitiba: ADEMADAN, 2009, 740 p.: il.; 18 cm.

MONTEIRO, Carlos Augusto de Figueiredo. A Interação Homem-Natureza no Futuro da Cidade. Geosul, n.14, ano VII, p.7-48, 2. sem. 1992.

A Geografia no Brasil (1934-1977): avaliação e tendências. São Paulo: Universidade de São Paulo. Instituto de Geografia, 1980. Série Teses e Monografias, n.37, 1980.

.Geossistemas: a história de uma procura. São Paulo: Contexto, 2000, 127 p.

MORAES, Antonio Carlos Robert. Meio Ambiente e Ciências Humanas. São Paulo: Hucitec, 1994, p.9-100.

MOREIRA, Rui. O Pensamento Geográfico Brasileiro: as matrizes clássicas originárias. São Paulo: Contexto, 2008, v.3, p.13-188.

MORIN, Edgar. Epistemologia da Complexidade. In: SCHMITMAN, Dora Fried. Novos Paradigmas, Cultura e Subjetividade. São Paulo: Cortez, 1996, p. 274-286.

. Cabeça Bem Feita - repensar a reforma reformar o pensamento. Tradução Eloá Jacobina- 5. ed. Rio de Janeiro: Betrand Brasil, 2001 p.128.

SANTOS, Milton. Metamorfoses do Espaço Habitado. São Paulo: Hucitec, 1991, p.61117.

TUAN, Yi-Fu. Espaço e Lugar: a perspectiva da Experiência. Tradução de Lívia de Oliveira. São Paulo: Difel, 1983, 249 p.

Topofilia: Um estudo da Percepção, Atitudes e Valores do Meio Ambiente. Tradução de Lívia de Oliveira. São Paulo: Difel, 1980, 288 p.

Enviado para publicação em setembro de 2010.

Aceito para publicação em outubro de 2010. 